\section{O pensamento social em saúde na América Latina: revisitando Juan César García}

\author{
Social thinking in health in Latin America: revisiting \\ Juan César García
} \author{
El pensamiento social en salud en Latinoamérica:
releyendo a Juan César García
}

Everardo Duarte Nunes 1

\section{Resumo}

O artigo elabora uma reconstituição do pensamento social em saúde do médico e sociólogo argentino Juan César García (1932-1984), analisando os principais trabalhos que trataram da sua obra e das suas atividades. Situa o seu pensamento nos dois campos que marcaram sua produção: a medicina social e as ciências sociais de 1960 até a segunda metade dos anos 80. Destaca-se a sua participação junto à Organização Pan-Americana da Saúde e a sua perspectiva de analisar a medicina social e as ciências sociais relacionando-as não somente ao contexto histórico, social, econômico e político latino-americano, mas dentro do enfoque do materialismo histórico: vinculação da medicina à estrutura social; influência da estrutura social na produção e distribuição da doença; análise interna da produção de serviços médicos; relação da formação de pessoal de saúde com o campo médico. Destaca que a sua obra pode ser, ainda hoje, referência quando se discutem temas como a educação médica, a formação de profissionais em saúde, o papel da ciência e da tecnologia, as ciências sociais no ensino médico, e aspectos históricos da saúde pública.

Social Medicine; Social Sciences; Medical Education
Medicina Social; Ciências Sociais; Educação Médica 


\section{Introdução}

Revisitar Juan César García no quadro do pensamento social em saúde na América Latina levanos a situar, mesmo que de forma bastante geral, a questão do que entendemos por pensamento social e em especial o latino-americano na modernidade.

Não se pretende retomar a construção do pensamento social na modernidade, mas tomar como ponto de partida a ideia de que essa construção é sociohistórica e tem como "principal preocupação a análise da realidade social, que necessita ser compreendida para ser transformada" 1 (p. 53). Ao mesmo tempo, essa ideia central tem de ser retrabalhada quando se volta para uma realidade específica - a América Latina. Recorro ao texto de Ianni 2 (p. 1) que, ao desvendar os “enigmas do pensamento social latino-americano", alerta que "devido à sucessão e contemporaneidade de situações mais ou menos similares, em diferentes países, são muitos os que se empenham em compreender e explicar, equacionar formulações alternativas, relativamente a problemas e dilemas da realidade histórica, em suas implicações socioculturais e político-econômicas". Prossegue o sociólogo, dizendo: "é muito provável que essas peculiaridades da história e do pensamento, em suas realizações e frustrações, sejam o que há de mais característico da modernidade latino-americana e caribenha. Uma modernidade entre barroca e mágica, indo-americano e afro-americana, ibérica e ocidental, original e esquizofrênica".

Associar essas duas dimensões - construção de um pensamento social em saúde e a realidade latino-americana - ao protagonismo de Juan César García é um ponto de partida para esta apresentação. Ao iniciá-la com as noções anteriores, assumo que essas são as marcas do projeto e das realizações de García ao longo de suas atividades e de sua produção científica. Para ele, projetos e realizações não podiam ser desvinculados de um campo teórico de reflexões, mas, ao mesmo tempo, deviam ser situados em um contexto histórico, geográfico, social, cultural, político e econômico, e este aspecto destaca-se, especialmente, a partir da segunda fase de sua produção intelectual (1966-1984).

Sem a possibilidade de aprofundar esse contexto, e correndo o risco da superficialidade, não se pode deixar de apontar que de 1930-1960, o que caracteriza a região do ponto de vista político é a chamada Era do Populismo, apresentando, segundo Grinschpun ${ }^{3}$, governos carismáticos e paternalistas, controladores dos movimentos sociais em uma economia que ficou conhecida como "modernização conservadora": Getúlio Vargas, no Brasil; Lázaro Cárdenas, no México; Juan
Domingo Perón, na Argentina; e Velasco Ibarra, no Equador, são exemplos desses governantes. Também, a partir do início dos anos 1950 até o final dos 1970, muitos países atravessaram uma fase de grande instabilidade política: são 16 golpes militares (ocorreram em diferentes momentos), duas revoluções socialistas - Cuba, 1959 e Nicarágua, 1979, instalação do governo socialista no Chile (1970-1973). Do ponto de vista da evolução econômica, ao longo do século XX, como analisa Bandeira 4 (p. 13), essa "pode ser vista como uma sucessão de períodos de expansão e de crise, ao mesmo tempo em que revela profundas transformações na estrutura econômica dos países da região". Segundo a autora, "entre 1960 e 1970, a taxa de crescimento média do produto da maior parte das economias era superior a 5\% ao ano. Esse desempenho se relacionava, em grande medida, ao rápido desenvolvimento industrial e às condições externas favoráveis. Os choques da segunda metade dos anos 70 e início dos 80 encerram essa fase, com uma recessão generalizada a partir de 1982".

Foi a partir da segunda metade dos anos 1980 que o trabalho de García passou a ser revisitado de várias formas - analisando a sua produção científica 5, organizando coletâneas de textos $6,7,8$, apresentando teses 9,10 , relatando a sua trajetória sociobiográfica 11 , relacionando o seu pensamento aos debates e movimentos da medicina social na América Latina 12,13,14,15,16,17, analisando os impactos da pesquisa sobre educação médica 18,19, relatando a sua atuação na Organização Pan-Americana da Saúde (OPAS) 9,10,20,21, realizando ciclos de debates, seminários e conferências (Fundación Internacional de Ciencias Sociales "Juan César García”, Quito/Equador, criada em 1984).

Embora a trajetória intelectual e a produção científica de García tenham sido mais analisadas a partir de 1984, seus trabalhos e sua influência se estendem a partir da segunda metade dos anos 1960, tanto no campo da medicina social como no das ciências sociais em saúde. A referência a esses dois campos é importante porque constitui as fronteiras que delimitam os principais trabalhos de García em seus estudos sobre as relações saúde/sociedade. Aliás, o próprio García 22 iria destacar que muitos foram os nomes adotados para caracterizar essas relações: medicina social, ciências sociais aplicadas à saúde, ciências sociais em saúde e sociomedicina, que se desdobrariam em abordagens disciplinares com base nas ciências sociais em sociologia médica, economia da saúde, antropologia médica e baseando-se nas ciências médicas em epidemiologia social, epidemiologia crítica, higiene social, nova saúde pública. Sem dúvida, é evidente que o pensamento 
social que se constrói na América Latina está entrecortado por esses distintos balizamentos.

Dessa forma, tomando-se, inicialmente, como ponto de referência as ciências sociais em saúde vamos situar, de forma geral, a produção nos anos 1950/1960, considerando-se que García inicia sua produção nos anos 1960.

Retomo como primeiras observações o fato de que até os anos 1960 a produção latino-americana, usando a expressão de Antônio Cândido 23, ao tratar da literatura, constituía-se de "manifestações" ("manifestações literárias” para distingui-las dos "sistemas literários", articulação entre autor, obra e público) sobre as questões do social em saúde. Essas "manifestações" foram levantadas num dos primeiros estudos sobre a produção das ciências sociais (então chamadas ciências da conduta) em saúde 24 e estavam relacionados a descrições de padrões sociais e culturais que afetam a saúde em pequenas comunidades campesinas e indígenas; havia poucos trabalhos sobre enfermidades e alguns voltados para projetos de mudanças planejadas em algumas comunidades. Essa primeira fase dos estudos apresenta uma produção de caráter antropológico e trabalha a chamada "medicina tradicional”. No Brasil, deve-se destacar na década de 1950 o papel dos folcloristas, dos antropólogos que trabalharam no Serviço Especial de Saúde (SESP) e sociólogos que se dedicaram à educação sanitária e aos estudos de comunidade. A presença mais intensa e a produção mais sistemática das ciências sociais em geral, e em saúde, no final dos anos 1950 e início dos 1960, serão resultado de vários fatores: a institucionalização da sociologia, a emergência dos projetos desenvolvimentistas e a inclusão das ciências do comportamento/ciências sociais no currículo de ensino médico. Nesse cenário começam a aparecer os primeiros trabalhos de García.

Um ponto já citado, mas que volto a enfatizar é que aliando a sua trajetória intelectual às suas atividades podemos traçar o próprio desenvolvimento da medicina social e de muitos aspectos pioneiros no campo das ciências sociais em saúde.

\section{Perfil}

Juan César García nasceu em Necochea, Argentina, em 7 de maio de 1932. Hoje, graças ao trabalho de pesquisas feitas na Argentina e com documentação inédita 11 é possível reconstituir alguns aspectos até então pouco conhecidos e divulgados sobre as suas origens e vida estudantil. Como nos contam Galeano et al. 11, Juan César vinha de uma família de baixos recursos econômicos; o pai trabalhava no campo e a mãe nos afazeres domésticos. Fez a escola secundária no Colégio Nacional de Necochea, à época dirigida por um socialista, e conviveu com seu tio (Julio Laborde) que foi dirigente do Partido Comunista de Mar Del Plata, secretário do Comitê Central do partido e jornalista. De Necochea, a família mudou-se para La Plata, a fim de que Juan César cursasse a universidade, cidade onde a família permaneceu de 1950-1959. Juan César completou o curso de medicina e participou da vida acadêmica (Centro de Estudiantes Necochenses, com a criação de um periódico universitário), realizou a residência em Pediatria (Hospital de Niños de la Plata "Sor María Ludovica”) e exerceu atividades no Centro de Salud de Berisso, participando de um estudo sobre as condições sanitárias de "pueblos" e cidades do interior. Iniciou o curso de jornalismo na Escuela de Periodismo, e não concluiu. Para esses autores, essa seria a "primera ruta", seguida da "secunda ruta", marcada pelo curso de sociologia na FLACSO (Facultad Latinoamericana de Ciencias Sociales) de Santiago de Chile/ Chile, realizado de 1960-1961, tendo lá permanecido até 1964, passagem pela Universidade de Harvard em 1965, e incorporação na OPAS, em Washington DC/Estados Unidos, em 1966, onde permaneceu até o seu falecimento, em 1984.

Como já apontamos, situamos a sua trajetória intelectual a partir de um momento inicial das produções em ciências sociais e medicina social começadas em 1961. Tomando essa data como referência do seu primeiro trabalho, estabelecemos uma divisão em dois momentos, 1961-1971 e 1972-1984, caracterizando os temas e algumas das principais propostas teóricas dos trabalhos. Essa cronologia permite que se apresente mesmo de forma resumida uma análise dos principais trabalhos produzidos.

Os primeiros estudos foram feitos quando García, entre 1960 e 1961, cursou ciências sociais, com uma bolsa de estudos na FLACSO. Em diversos momentos ele se refere a esse período, quando chegou inclusive a ser, por indicação de Peter Heinz, diretor da Escuela Latinoamericana de Sociología, parte do corpo docente em Teoria Social. A sua participação em uma investigação sobre as relações do ambiente de trabalho sobre o comportamento dos indivíduos, que era um projeto internacional, o indicaria para Harvard, em 1965. Destaco, nesse momento, alguns trabalhos que se voltaram para o estudo das relações médico/paciente - dissertação de mestrado na Escuela Latinoamericana de Sociología 25. Nessa época, García conviveu com vários estudantes (na sua turma foram 19 diplomados, 15 homens e quatro mulheres) que se tornariam referências em seus campos de pesquisa, como Aníbal 
Quijano (1928), peruano, com estudos sobre colonialismo e nacionalismo; Cecília Muñoz, psicóloga colombiana, pesquisas em psicanálise, infância e adolescência; Hugo Zemelman (1931), chileno, professor no México, com temas de pesquisas em movimentos sociais, metodologia e epistemologia; Carlota Rios, chilena, advogada, que se dedicaria ao direito sanitário, com quem Juan César se casaria. Há inúmeros relatos sobre a FLACSO, mas destaco: Péres Brignoli 26, Fuenzalida 27, e Franco 28.

Dois outros trabalhos sobre as bases sociológicas das relações médico/paciente e o comportamento das elites médicas também foram publicados no início dos anos 1960 29,30. Lembramos que naquele momento o tema do relacionamento médico/paciente era destaque na sociologia médica norte-americana, mostrando a atualidade das pesquisas de García.

Ainda nessa década e início dos anos 70, outros estudos e pesquisas de García se orientam para a educação médica $31,32,33$, estudante de medicina ${ }^{34}$, ensino das ciências sociais ${ }^{35}$, e doenças 36 .

Todos esses trabalhos abrem uma ampla discussão sobre o ensino, a busca de paradigmas para as ciências sociais (às vezes muito próximos dos modelos médicos) que pudessem atrair o interesse dos alunos para os aspectos sociais e toda uma discussão sobre a formação de recursos humanos em saúde que culminaria com o livro $L a$ Educación Médica en la América Latina 37. Antes, García 31, usando o tempo como variável, elabora uma tipologia das escolas médicas em: inovadoras, as que respondem rapidamente às novas ideias, as que respondem mais lentamente, e as procrastinadoras ou resistentes às mudanças.

De um modo geral, pode-se dizer que nesse período, como analisa Franco 38 (p. x), de "uma afinidade inicial com as correntes então modernas da sociologia e da filosofia, em especial o funcionalismo neopositivista, avança para o estruturalismo que no campo da saúde é representado pelos trabalhos de Michel Foucault e se aproxima a uma interpretação dialética da realidade". Na mesma linha de pensamento, Galeano et al. 11 (p. 295) apontam que "nestes trabalhos iniciais dos anos 60, García recolhe categorias da sociologia norte-americana, mas também uma análise crítica do enfoque centrado na 'resolução de problemas' práticos da medicina". Deve-se acrescentar que García conhecia profundamente a literatura funcionalista em medicina, levando-o a organizar uma coletânea de textos traduzidos para o espanhol e não publicados 39 . Nessa coletânea aparecem textos de Parsons, Simmons, Suchman, Blackwell, Wilson e outros que são pioneiros da sociologia médica (anos 1950 e 1960) com definições e categorias de análises que foram da maior importância na aproximação das ciências sociais com a medicina, tais como: sick role, illness behavior, sick role stage etc.

Sem dúvida, o fato de ter-se tornado consultor da OPAS, em 1966, também concorreu para que as atividades de García se voltassem para a formação de profissionais de saúde, visto que ele se juntou ao departamento de recursos humanos dessa instituição. Não se pode falar desse departamento sem a menção a José Roberto Ferreira 20 que, em entrevista para o Projeto História da Cooperação Técnica em Recursos Humanos em Saúde no Brasil, traça a história do departamento, no qual trabalhou durante 22 anos. Nesse depoimento, ele relata as diversas transformações pelas quais o departamento passou durante diferentes administrações da OPAS, e destaca os seminários que foram organizados sobre Educação em Saúde que reunia diretores de escolas, profissionais de saúde, durante dois a três meses na sede da Organização, em Washington DC. Salienta o papel importante nessas atividades de Juan César García, Miguel Marques e Jorge Andrade.

Nessa época, o projeto de investigação que se desenhava, sob o patrocínio da Fundação Milbank, era o de estudar a medicina preventiva e social na América Latina que se transformaria em um estudo sobre a educação médica, antes mencionado. Esse trabalho que constitui um marco das pesquisas em educação médica, realiza uma equilibrada análise empírico-teórica tomando como referência a pesquisa em 100 escolas médicas (de um total de 151) traçando um quadro sobre as suas atividades de ensino e seus planos curriculares. Descreve os agentes de ensino - estudantes e corpo docente, sendo que dos primeiros elabora um perfil com base nas etapas que os levaram a se decidir pela carreira médica. Depreende que estudantes e corpo docente constituem dois grupos bem definidos e com interesses diferentes 37 . Para o autor, essa análise - infraestrutura - se completa com a da supraestrutura - a escola médica (forma institucional para a produção de médicos).

A década de 70 apresentaria dois outros fatos marcantes que foram a realização da 1 a Reunião de Cuenca, Equador, e a divulgação do trabalho Las Ciencias Sociales en Medicina 40.

Data desse momento a perspectiva de analisar a medicina social e as ciências sociais relacionando-as não somente ao contexto histórico, social, econômico e político latino-americano, mas dentro do enfoque do materialismo histórico. Destaco os seguintes pontos: vinculação da medicina à estrutura social; influência da estrutura social na produção e distribuição da doença; 
análise interna da produção de serviços médicos; relação da formação de pessoal de saúde com o campo médico. Para García, existem três processos que se inter-relacionam: a produção de conhecimentos científicos, de pessoal de saúde e de serviços de saúde, que variaram historicamente e produziram dois tipos de serviços: o artesanal e o burocrático.

Durante a década de 1970, além dos trabalhos citados, são publicados artigos sobre as origens da medicina social 41 , o conceito e a história da medicina comunitária 42 , a escolha da enfermagem como profissão 43 , a articulação da medicina e da educação na estrutura social 44.

O curto período de 1980-1984 foi de intensa produção, marcado pela preocupação de um maior aprofundamento da abordagem históricodialética e a utilização de extensa documentação - documentos oficiais da década de 1970 (Plano Decenal de Saúde para as Américas e informes sobre política de saúde do Banco Mundial). Destacam-se os estudos sobre a história das instituições de pesquisa na América Latina 45 e sobre as relações entre a medicina e o estado, de 1880 a 1930 46,47. No primeiro, salienta que "as influências externas na orientação das investigações se apresentam de forma menos direta à medida que a ciência adquire uma maior autonomia em relação a outros setores da sociedade como a economia e a política" 45 (p. 92). No segundo, trabalha a vinculação da medicina ao capitalismo; e fatores na criação dos departamentos nacionais de saúde. Ao analisar o papel da Comissão Internacional de Saúde da Fundação Rockefeller e suas vinculações com os programas sanitários, enfatiza os aspectos econômicos das fundações em suas ações na erradicação das enfermidades infecciosas. Análise crítica sobre os modelos teóricos de análise das fundações, incluindo a vinculação às questões econômicas, pode ser vista em Faria 48. Também nesse período aparecem três estudos teóricos, um sobre as correntes de pensamento no campo da saúde 49 , outro sobre o conceito de trabalho em medicina 50 , e um terceiro sobre a "doença da preguiça e a fadiga patológica" 51. Destaque-se, ainda, a preocupação com o campo científico e sua construção, que aparecem no amplo levantamento sobre as ciências sociais $52 \mathrm{e}$ sobre a investigação no campo da saúde na América Latina 53.

Em 1983, García organiza a 2a Reunião de Ciências Sociais em Saúde, em Cuenca/Equador, cujos trabalhos serão publicados por Nunes 5 incluindo o último estudo escrito por García 22. Os trabalhos apresentados nesse seminário traduzem o avanço que o campo das ciências sociais teve uma década após a 1a Reunião de Cuenca (1972), refletindo quanto havia se desen- volvido o ensino, as disciplinas do social, as áreas temáticas, trabalhos que marcam a profunda influência exercida por García junto aos grupos de profissionais da saúde e de cientistas sociais do continente. Com cerca de 30 participantes, a reunião foi realizado de 29 de novembro a 3 de dezembro, debatendo as tendências e perspectivas das ciências sociais pós-anos 1970, além de um extenso panorama sobre as ciências sociais, com uma série de dados e análises, estudos específicos sobre as realidades nacionais de quatro países: Brasil, Equador, México, Venezuela; as disciplinas: antropologia, economia, psicologia social, sociologia; as áreas temáticas: epidemiologia, trabalho, mortalidade infantil, doenças tropicais, profissionais de saúde, tecnologia em saúde, planejamento em saúde, organização dos serviços, pessoal de saúde, enfermagem, ensino, problemas metodológicos.

Em janeiro de 1984, Juan César realiza a sua última viagem. Vai à Argentina e, como relata José Romero Teruel 54, seu companheiro de trabalho em Washington e dessa viagem, ali reencontrou amigos que retornavam ao país, em processo inicial de redemocratização, visitou a universidade, o Conselho de Ciências e Técnicas, o Ministro de Saúde (Aldo Neri), caminhou pelas ruas centrais de Buenos Aires e visitou livrarias. Ao regressar aos Estados Unidos, com fortes dores articulares, foi internado em um hospital e depois transferido para a sua residência e não voltou mais ao seu escritório na OPAS.

Em junho de 1984, gravemente enfermo, García escreveu o seu último trabalho 22 - espécie de testamento no qual faz uma reflexão sobre a medicina social, as ciências sociais e o papel da OPAS, que é entregue a mim poucos dias antes de seu falecimento em 8 de junho. Em 12 de junho, seu corpo foi transportado para a Argentina onde foi sepultado.

\section{O legado}

Profundamente identificado com a América Latina, suas contradições e problemas, García percorreu todo o continente em inúmeras viagens e trouxe uma contribuição ao pensamento social em saúde, que no seu conjunto e em aspectos específicos sobrevive após quase trinta anos de sua morte. Como vimos, foi durante as décadas de 1960, 1970 e 1980 que se desenvolveu na América Latina o aparato conceitual que seria indispensável na construção da medicina social em muitos países, e esta foi, sem dúvida, uma das suas realizações. Buscando encontrar uma base comum a esse processo, Iriarte et al. 55 apontam que três são os eixos centrais na construção de 
um pensamento em saúde na América Latina: (1) "Considerar a população e as instituições sociais como totalidades cujas características transcendem as dos indivíduos que as compõem" (p. 130) e neste sentido, as principais características analíticas são: reprodução social, classe social, produção econômica, cultura, etnia, gênero etc.; (2) Conferir "centralidade e tornar explícita a teoria em todo o processo de investigação ou de intervenção em torno de um problema" (p. 130); e (3) Abordar "a causalidade de forma mais complexa na qual as condições sociais e históricas são consideradas como determinantes estruturais, ou seja, que existem antes do problema analisado e sua compreensão permite especificar as dimensões do mesmo" (p. 131).

Sem dúvida, no contexto latino-americano da segunda metade dos anos 1960 até a primeira metade dos anos 1980, apesar de condições adversas como regimes de exceção, ditaduras militares, repressão às liberdades individuais, abriu-se um amplo debate sobre as questões de saúde, em especial como assinala Arango 15 "de discussão, estudo, investigação e formação de recursos humanos na América Latina, (que) se articulou a partir das ciências sociais em um amplo trabalho de análise crítica e propostas teóricometodológicas reconhecidas por seus aportes para a construção de um pensamento social em saúde, transcendendo ao biologismo e ao funcionalismo hegemônico".

Nesse cenário, muitos se destacaram e trouxeram contribuições das mais importantes para repensar o social em saúde e "aplicá-lo" às difíceis e desiguais realidades do continente latinoamericano, mas ao revisitar Juan César García a sua presença se destaca como pensador inovador e articulador de grupos e instituições. Isso estará presente quando se discute a educação médica, a formação de profissionais em saúde, o papel da ciência e da tecnologia, as ciências sociais no ensino médico, aspectos históricos da saúde pública na América Latina, os movimentos em saúde. Almeida 19, ao analisar as relações entre tecnologia e medicina e seus impactos sobre a educação médica, tomando como eixo o desenvolvimento latino-americano de educação médica nas duas últimas décadas do século XX, destaca o trabalho de García nos anos 70. Ao estabelecer um paralelo na forma como ele havia estudado o processo de formação de médicos e as novas realidades assinala: “... as escolas médicas, principalmente através dos seus hospitais universitários, incorporam condutas e relações que servem como poderosos instrumentos de reprodução do modelo dominante de organização dos serviços de saúde e práticas profissionais" 19 (p. 71). Ressalta, porém, que a OPAS e a Federación Panamericana de Aso- ciaciones de Facultades y Escuelas de Medicina (FEPAFEM) não ficaram alheias à "incorporação tecnológica indiscriminada" e lançaram um alerta crítico sobre esta questão. Certamente, a realidade latino-americana do final dos anos 1960 quando foi realizado o estudo de García sobre a educação médica e a do século XXI tem de ser considerada, mas os reflexos daquela pesquisa ainda são evidentes. Em 1992, Ferreira 56 escreveu sobre o impacto dessa investigação. Como bem analisa, "o estudo de Juan César García rompeu com as práticas condutistas e o enfoque sistêmico prevalente em sua época, desenvolvendo um estudo histórico-estruturalista, que como ele mesmo sublinhava: "mais que intervir na evolução dos processos com fins utilitários imediatos, havia que rastrear sua compreensão e a identificação dos fatores que os dinamizavam'” 56 (p. 11). Ao ressaltar a forma como esse trabalho foi concebido e realizado, especialmente quando se refere à influência hegemônica do padrão de prática na formação médica, no contexto das transformações do processo produtivo, escreve: “César García nos deixou como legado esta forma de enfocar o objeto de estudo, a qual permitiu e segue possibilitando aos estudiosos da matéria em toda a América Latina, gerar um mais amplo conhecimento de toda essa problemática" 56 (p. 12).

Da mesma forma, a contribuição de García para o campo dos estudos sobre ciência e tendências da pesquisa biomédica e social e do desenvolvimento científico e tecnológico não pode ser marginalizada, e abriu espaço para um melhor conhecimento da situação na América Latina. Ressalte-se o pioneirismo das contribuições trazidas ao repensar a questão dos indicadores da produção científica, quando analisou, a partir de 1978, a situação de 11 países da América Latina 53 e da primeira sistematização bibliográfica sobre as ciências sociais em saúde 52 . Pelegrini 57 ao reconstituir a formação da área de política científica na OPAS destaca que esta área esteve inicialmente vinculada à de recursos humanos, e por volta de 1981 se institucionalizou dentro da Organização, graças aos esforços de García.

Sem dúvida, essa atividade era o coroamento de uma preocupação que atravessou toda a atividade de García - a divulgação do conhecimento, para a qual ele se serviu de várias formas: traduzindo e enviando cópias de artigos, escrevendo cartas e sugerindo leituras e realizando levantamentos bibliográficos. Era assim que ele fazia chegar aos amigos as suas sugestões. Lembro que em 1971, em uma das cartas ele sugeria que se fizessem exercícios sobre a metodologia utilizada pelos "grandes mestres" das ciências sociais, selecionando e realizando um exercício sobre o primeiro capítulo de $O$ Capital. Além de pedir 
comentários, fazia sugestões para outros trabalhos, por exemplo, a Psicologia de las Masas, de Freud, e "também (por que não?) seria útil analisar a forma de trabalho de Sherlock Holmes na novela 'Estudo em Escarlate', de Arthur Conan Doyle" 6 (p. 30). Felizmente, parte dessas cartas foi organizada por Barreto 58 , referente ao ano de 1973. Nelas afloram sugestões de leituras de autores como Bourdieu, Passeron, Boltanski, Berlinguer, Laura Conti, Ivan Illich, Bachelard e outros, e de pesquisas. Muitas vezes aparecem críticas, como, por exemplo: “Durante los últimos meses he estado leyendo vários artículos y monografias sobre historia de la medicina y de la educación médica en América Latina. En la mayoría de ellos prima un estilo panfletário en que se afirman cosas para las cuales no se presentan pruebas o se distorsionan hechos. Esto es aún más lamentable porque los autores presentan un cuerpo teórico (en líneas generales) adecuado" (García, carta de 5 de julho de 1973).

Sem dúvida, são inegáveis as contribuições de García para a construção de um pensamento social em saúde do ponto de vista teórico conceitual, com uma contribuição pioneira e original.

Ao lado, ou conjuntamente, a esse percurso no campo acadêmico, ressalta-se o protagonismo de García como articulador na formação de quadros para o campo da saúde e, como destaca Figueiroa 59, preocupação presente a partir dos seus primeiros trabalhos quando compara e discute teoricamente a prática médica em países desenvolvidos e subdesenvolvidos, apontando o elevado prestígio do médico nas sociedades subdesenvolvidas e o caráter mercantilista de certas especializações ${ }^{30}$. Anos depois, García \& Verderese ${ }^{43}$ pesquisariam a questão da escolha da enfermagem como profissão, um dos primeiros estudos empíricos sobre a profissão na América Latina. Destaque-se a sua presença marcante no encaminhamento da organização dos primeiros cursos de pós-graduação em medicina social no México, 1973, e Rio de Janeiro, 1974.

Os pontos abordados dimensionam a extensão e a qualidade da produção de García, com temas que não perderam a sua atualidade e, numa tentativa de ilustrar com as próprias palavras do autor a sua participação para o campo científico da saúde, selecionamos alguns trechos que são marcas do seu pensamento.

"El intento de hacer la história de la ciência en los países de América Latina no solo tiene por objeto resaltar la contribución de la regiõn al desarrollo de la ciência sino, fundamentalmente, descubrir las leyes que rigem la producción científica. En este último sentido, el análisis histórico forma parte de cualquier estúdio de la situación de la ciência" 45 (p. 79).
"Las prácticas en el campo de la salud y en el de la investigación, sus relaciones recíprocas y com la estructura social, y las categorias que surgen, formando la trama sobre la cual se teje el discurso sobre dichas prácticas, adquieren sentido com el estúdio de la totalidad social" 45 (p. 79).

"Estimamos, también, que la producción de conocimientos científicos constituye una práctica central de la Universidad y um componente fundamental del proceso de enseñanza-aprendizage [...] La participación de la Universidad en la prestación de servícíos debería vincularse com la investigación y dar lugar a proposiciones de nuevas prácticas profesionales que satisfagan colectivamente las necesidades de la población" 60 (p. 314-5).

Certamente, como reconhecido por todos os estudiosos da medicina social latino-americana e da saúde coletiva no Brasil, as três últimas décadas, que coincidem com o período desta análise sobre García, foram de extraordinário crescimento tanto na produção científica como no ensino, em especial o de pós-graduação, e na extensão às políticas de saúde. Portanto, consolida-se a construção de um pensamento social em saúde com as características regionais que lhe são próprias, com a participação de diversos campos disciplinares como a história, as ciências sociais, a economia, a demografia, a epidemiologia, a epistemologia, que trarão novos arranjos metodológicos e teóricos. Nesse sentido, uma das críticas à abordagem de García foi o fato de ter enfatizado as macroanálises estruturais e, como escreve Mercado-Martínez ${ }^{61}$, rejeitando a orientação interpretativa (interacionismo simbólico, fenomenologia e etnometodologia, entre outras) como válida para estudar fenômenos sociais e médico-sanitários, não destacando as pesquisas qualitativas. Como vimos em outros momentos desta exposição, nos anos 1970 e 1980 a grande questão era oferecer uma interpretação totalizante dos fenômenos sociais e o arcabouço teórico encontrado era o oferecido pelo marxismo, que produziu extensa literatura na América Latina, além dos trabalhos de García; por exemplo, no Brasil os estudos sobre o trabalho médico e educação médica; no Equador sobre as relações classe social e perfil epidemiológico; no México sobre o processo de trabalho; na Argentina a reprodução social e muitos outros. Nesse sentido, inegavelmente, constata-se a relevância das abordagens históricoestruturais de García.

Penso que Granda 16 ao fazer um retrospecto sobre a medicina social na América Latina, sintetizou de maneira muito feliz a abordagem que García imprimiu a este campo: o compromisso político com a mudança, a saúde-doença como fato social, a importância da ciência na construção do 
campo, a responsabilidade do estado no campo da saúde, cuja validade não foi contestada ao longo dos anos. Mais ainda, como lembra Mercer 62, um dos primeiros a abordar a medicina social como campo intelectual, na perspectiva de Bourdieu, Juan César ao encerrar a reunião de Cuenca, 1983, não somente disse que a partir daquele momento aquele ciclo se encerrava, mas que "os próximos encontros iriam ser caracterizados pelo pluralismo. Isso implicava conservar a identidade da medicina social refinando seus recursos explicativos, mas também a manutenção de uma ampla convocatória e a disposição de escutar e compartilhar espaços com o diferente, que não é necessariamente o inimigo" 62 (p. 13).

\section{Conclusões}

Recentemente, o sociólogo canadense Marcel Fournier 63 (p. 172), grande especialista na obra e vida de Émile Durkheim e Marcel Mauss, comentou a citação do próprio Durkheim que "o homem é sua obra", acrescentando o seguinte: "a obra é, no entanto, tanto uma expressão direta de uma vida quanto um reflexo de uma sociedade ou uma época. A vida e a obra estão interligadas com a sociedade, mas também distantes dela. O desafio para o biógrafo social é reconstruir o contexto, a 'superfície social' no qual os indivíduos atuam em uma pluralidade de setores ou campos, em cada momento". Essa reflexão Fournier deriva de sua própria atividade como sociólogo que trabalha com a biografia como forma de conhecimento sociológico. Sem a pretensão de elaborar a sociobiografia de García, que em grande parte pode ser encontrada em Galeano et al. 11, fizemos algumas aproximações iluminadas pela abordagem de Fournier. De forma geral, elas se orientaram para os seguintes pontos: descrição cronológica da vida e trabalhos, o que evita uma abordagem (exclusivamente) temática; apresentação da obra como um todo e em certa extensão dos colaboradores, assim como os debates sobre os trabalhos; contextualização institucional do autor.

Sem dúvida, o rico material pesquisado por García, sua correspondência, os documentos oficiais e as entrevistas de muitos de seus contemporâneos ainda constituem fonte para outras abordagens além daquelas tratadas nesta apresentação. Mas, o que gostaria de deixar neste final é que além da obra, que foi a tônica desta apresentação, Juan César sobressai no panorama da medicina social como o intelectual crítico e objetivo, sempre pronto a compartilhar seu conhecimento e ideias, extremamente generoso e amigo.

\section{Resumen}

El artículo presenta una reconstrucción del pensamiento social en salud del médico y sociólogo argentino Juan César García (1932-1984), analizando los principales estudios sobre su trabajo y sus actividades. Sitúa su pensamiento en los campos que marcaron su producción: la medicina social y las ciencias sociales desde 1960, hasta mediados de los 80, participación en la Organización Panamericana de la Salud y se hace hincapié en su perspectiva para analizar esos campos en relación con el contexto histórico, social, económico y político latinoamericano, dentro del enfoque materialista histórico: vinculación de la medicina con la estructura social, influencia de la estructura social en la producción y distribución de la enfermedad, el análisis interno de la producción de servicios médicos; formación del personal en el campo de la salud. Destaca que la obra de García puede ser hoy referencia cuando se habla de temas como la educación médica, la formación de profesionales de la salud, el papel de la ciencia y la tecnología, las ciencias sociales en la educación médica, los aspectos históricos de la salud pública.

Medicina Social; Ciencias Sociales; Educación Médica 


\section{Agradecimentos}

Este trabalho é resultado parcial do Projeto História da Saúde Coletiva e da Sociologia da Saúde, que conta com o financiamento do CNPq (bolsa de produtividade Pesquisador IA). Uma versão inicial foi apresentada no 10o Congresso Brasileiro de Saúde Coletiva, Porto Alegre, Rio Grande do Sul, Brasil, em novembro de 2012.

\section{Referências}

1. Lara R. Pensamento social da modernidade e ontologia materialista. Verinotio - Revista On-Line de Educação e Ciências Humanas 2009; 10. http:// www.verinotio.org/conteudo/0.3944390345313. pdf.

2. Ianni O. Enigmas do pensamento latino-americano. http://www.iea.usp.br/artigos (acessado em Ago/2012).

3. Grischpun I. América séc. XX. http://www.unifica do.com.br (acessado em 04/Nov/2012).

4. Bandeira AC. Reformas econômicas, mudanças institucionais e crescimento na América Latina. http://www.bndes.gov.br/SiteBNDES/export/ sites/default/bndes_pt/Galerias/Arquivos/co nhecimento/premio/pr242.pdf (acessado em Out/2012).

5. Nunes ED. As ciências sociais em saúde na América Latina: tendências e perspectivas. Brasília: Organização Pan-Americana da Saúde; 1985.

6. Nunes ED. As contribuições de Juan César García às ciências sociais em saúde. In: Nunes ED, organizador. Juan César García: pensamento social em saúde na América Latina. São Paulo: Cortez Editora; 1989, p. 11-37.

7. Nunes ED, Rodriguez MI, Franco S. J. C. García: pensamiento social em salud en América Latina. México DF: Organización Panamericana de la Salud/Interamericana; 1994.
8. Marquez M, Rojas-Ochoa F, organizadores. Juan César García: su pensamineto en el tiempo, 19842007. La Habana: Sociedad Cubana de Salud Pública/Ateneo "Juan César García”; 2007.

9. Castro JL. Protagonismo silencioso: a presença da Opas na formação de recursos humanos em saúde no Brasil. http://bdtd.bczm.ufrn.br/ tedesimplificado/tde_arquivos/9/TDE-2008-1031T041020Z-1510/Publico/JaneteLC.pdf (acessado em Set/2012).

10. Leal MB. Saúde coletiva em debate: a brasilidade de muitos encontros [Dissertação de Mestrado]. Rio de Janeiro: Instituto de Medicina Social, Universidade do Estado do Rio de Janeiro; 2009.

11. Galeano D, Trotta L, Spinelli H. Juan César García y el movimiento latinoamericano de medicina social: notas sobre uma trayectoria de vida. Salud Colect 2011; 7:285-315.

12. Tajer D. Latin American social medicine: roots, development during the 1990s and current challenges. Am J Public Health 2003; 93:2023-7.

13. Lopez O, Peña F. Salud y sociedad. Aportaciones del pensamiento latinoamericano. Medicina Social 2006; 1:82-102.

14. Rodriguez MI. De la salud individual a la salud global: la busqueda de um mundo mejor, 2007. http:// www.elagora.org.ar/site/documentos/PonenciaIsabel-Rodriguez.pdf (acessado em Set/2012). 
15. Arango Y. Referentes socio-históricos latinoamericanos: contribución a los fundamentos políticos de la promoción de salud. Rev Cuba Salud Pública 2008; 34:0-0.

16. Granda E. ALAMES turns 24. Social Medicine 2008; 3:165-72.

17. Hermida C. Juan César García y la medicina social en América Latina. http://www.docstoc. com/docs/116104228/Foro-Salud (acessado em Ago/2012).

18. Ferreira JR. A educação médica na América Latina 20 anos após o estudo de Juan César García. Rev Bras Educ Méd 1992; 16:11-5.

19. Almeida MJ. Tecnologia e medicina: uma visão da academia. Bioética 2000; 8:69-77.

20. Ferreira JR. Entrevista. Observatório História e Saúde. http://observatoriohistoria.coc.fiocruz.br/ php $/$ level.php?lang=pt\&component $=43 \&$ item $=3$ (acessado em Out/2012).

21. Pires-Alves F, Paiva CHA. Recursos críticos: história da cooperação técnica Opas-Brasil em recursos humanos para a saúde (1975-1988). Rio de Janeiro: Editora Fiocruz; 2006.

22. García JC. Juan César García entrevista Juan César García. In: Nunes ED. As ciências sociais em saúde na América Latina: tendências e perspectivas. Brasília: Organização Pan-Americana da Saúde; 1985. p. 21-8.

23. Cândido A. Formação da literatura brasileira. São Paulo: Itatiaia; 1975

24. Badgley RF, Schulte M. Social science teaching programs in Latin American medical schools. Milbank Mem Fund Q 1966; 44(2 Suppl):187-97.

25. García JC. Variación en el grado de anomia en la relación medico-paciente en un hospital [Dissertação de Mestrado]. Santiago de Chile: Escuela Latinoamericana de Sociología; 1961.

26. Pérez Brignoli H. Los 50 años de Flacso: desarrollo de las Ciencias Sociales en América Latina. http://unpan1.un.org/intradoc/groups/public/ documents/icap/unpan037250.pdf (acessado em Set/2012).

27. Fuenzalida E. La primera FLACSO (1957-1966): cooperación internacional para la actualización de la sociologia en América Latina. http://new.flac so.cl/flacso/biblos.php?code=2871 (acessado em Set/2012).

28. Franco R. La FLACSO clásica (1957-1973). Vicisitudes de las ciencias sociales latinoamericanas. Santiago de Chile: FLACSO/Editorial Catalonia; 2007.

29. García JC. Sociología y medicina: bases sociológicas de las relaciones médico-paciente. Cuad Méd Soc 1963, 12:11-5.

30. García JC. Comportamiento de las elites médicas em una situación de subdesarrollo. Cuad Méd Soc 1964; 5:20-5.

31. García JC. Innovations in medical education in Latin America. III Annual Meeting of Health Sciences Education. Information Center. Washington DC: Pan American Health Organziation; 1971.

32. García JC. Profile of medical education in Latin America. Int J Health Serv 1971; 1:37-59.

33. García JC. Características generales de la educación médica en la América Latina. Educ Méd Salud 1969; 3:267-316.
34. García JC. La decisión de estudiar medicina. Educ Méd Salud 1971; 4:277-94.

35. García JC. Paradigmas para la ensenãnza de las ciencias sociales en las escuelas de medicina. Educ Méd Salud 1971; 5:130-48.

36. García JC. Aspectos psicológicos, sociales y culturales de las enfermedades venereas. Bol Oficina Sanit Panam 1971; 70:79-94.

37. García JC. La educación médica en la América Latina. Washington DC: Organización Panamericana de la Salud; 1972.

38. Franco S. Presentación. In: Nunes ED, Rodriguez MI, Franco S, organizadores. J. C. García: pensamiento social en salud en América Latina. México DF: Organización Panamericana de la Salud/Interamericana; 1994. p. ix-xi.

39. García JC. Coletânea de textos. Washington DC Organización Pan-Americana da Saúde; 1971.

40. García JC. As ciências sociais em medicina. In: Nunes ED, organizador. Juan César García: pensamento social em saúde na América Latina. São Paulo: Cortez Editora; 1989. p. 51-67.

41. García JC. 1848: o nascimento da medicina social. In: Nunes ED, organizador. Juan César García: pensamento social em saúde na América Latina. São Paulo: Cortez Editora; 1989. p. 159-66.

42. García JC. Medicina comunitária: concepto y história. Washington DC: Organización Panamericana de la Salud; 1974.

43. García JC, Verderese O. La decisión de estudiar enfermería. Educ Méd Salud 1974; 8:390-407.

44. García JC. La articulación de la medicina y de la educación en la estrucutura social. In: Nunes ED, Rodriguez MI, Franco S, organizadores. J. C. García: pensamiento social en salud en América Latina. México DF: Organización Panamericana de la Salud/Interamericana; 1994. p. 277-308.

45. García JC. Historia de las instituciones de investigación en salud en América Latina 1880-1930. In: Nunes ED, Rodriguez MI, Franco S, organizadores. J. C. García: pensamiento social en salud en América Latina. México DF: Organización Panamericana de la Salud/Interamericana; 1994. p. 79-94.

46. García JC. La medicina estatal en América Latina (1880-1930) - 1a parte. Revista Latinoamericana de Salud 1981; 1:73-104

47. García JC. La medicina estatal en América Latina (1880-1930)- 2a parte. Revista Latinoamericana de Salud 1982; 2:102-17.

48. Faria LR. Os primeiros anos da reforma sanitária no Brasil e a atuação da Fundação Rockefeller (1915-1920). Physis (Rio J.) 1995; 5:109-29.

49. García JC. Medicina e sociedade: correntes de pensamento no campo da saúde. In: Nunes ED, organizador. Juan César García: pensamento social em saúde na América Latina. São Paulo: Cortez Editora; 1989. p. 68-99.

50. García JC. A categoria trabalho na medicina. In: Nunes ED, organizador. Juan César García: pensamento social em saúde na América Latina. São Paulo: Cortez Editora; 1989. p. 100-24.

51. García JC. The laziness disease. Hist Philos Life Sci 1981; 3:31-59. 
52. Badgley RF, Bravo G, Gamboa C, García JC. Bibliografía latinoamericana sobre ciencias sociales aplicadas a salud. Washington DC: Organización Panamericana de la Salud; 1980.

53. García JC. La investigación en el campo de la salud en once países de la América Latina. Washington DC: Organización Panamericana de la Salud; 1982.

54. Teruel JR. Una visita de despedida a Argentina y a América Latina. In: Marquez M, Rojas-Ochoa F, organizadores. Juan César García: su pensamineto en el tiempo, 1984-2007. La Habana: Sociedad Cubana de Salud Pública/Ateneo "Juan César García”; 2007. p. 19-20.

55. Iriarte C, Waitzkin H, Breilh J, Estrada A, Mehry EE. Medicina social latinoamericana: aportes y desafios. Rev Panam Salud Pública 2002; 12:128-36.

56. Ferreira JR. La educación médica em América Latina y el pensamiento de Juan César García. In: Marquez M, Rojas-Ochoa F, organizadores. Juan César García: su pensamineto en el tiempo, 1984-2007. La Habana: Sociedad Cubana de Salud Pública/ Ateneo “Juan César García”; 2007. p. 77-81.

57. Pelegrini A. Entrevista (15/03/2005). História da cooperação técnica em recursos humanos em saúde no Brasil. http://observatoriohistoria.coc. fiocruz.br/php/level.php?lang=pt\&component $=4$ 3\&item=3\#e1f1lb (acessado em Out/2012).
58. Barreto D. "Cartas a los amigos". Rev Inst Juan Cesar Garcia 1994; 4:60-71.

59. Figueiroa JL. El pensamiento latinoamericanista de Juan César García. In: Marquez M, Rojas-Ochoa F, organizadores. Juan César García: su pensamineto en el tiempo, 1984-2007. La Habana: Sociedad Cubana de Salud Pública/Ateneo "Juan César García”; 2007. p. 29-32.

60. García JC. Consideraciones sobre el marco de la educación médica In: Nunes ED, Rodriguez MI, Franco S, organizadores. J. C. García: pensamiento social en salud en América Latina. México DF: Organización Panamericana de la Salud/Interamericana; 1994. p. 309-16.

61. Mercado-Martínez FJ. Investigación cualitativa en América Latina: perspectivas críticas en salud. International Journal of Qualitative Methods 2002; 1:61-73.

62. Mercer H. La medicina social en debate. Cuad Méd Soc (Ros.) 1987; 42:5-13.

63. Fournier M. Is there anything new to say about Émile Durkheim and Marcel Mauss? International Sociology 2012; 27:170-8.

Recebido em 31/Jan/2013

Aprovado em 15/Mai/2013 